\title{
MAINTAINABILITY, DESIGN PROCESSES AND BUILDING SERVICES: A CASE STUDY OF SELECTED BUILDINGS IN THE RIVERS STATE UNIVERSITY
}

\author{
${ }^{1}$ Chioma Okandu ${ }^{*},{ }^{2}$ Chizy Akani, PhD and ${ }^{2}$ Warebi Brisibe, PhD
}

1. Post graduate Candidate, Department of Architecture, Rivers State University, PortHarcourt

2. Lecturer, Department of Architecture, Rivers State University, Port-Harcourt

\begin{abstract}
The paper examines the issues of building maintenance of public buildings from an architectural design-based perspective. It considered the critical role design plays in achieving the optimal functionality of building services throughout the building life span. Design related elements and components which facilitate maintainability are discussed. Institutional buildings at the university in their current state are considered against these dimensions. The research adopts a case study/ review approach. The study focused on multistory structures existing in the university. Findings of the study reveal poor considerations for maintainability in design processes, resulting in inefficiency of building services on a large scale.
\end{abstract}

Key words: Maintainability, Building Maintenance, Building Services, Design Process 


\section{INTRODUCTION}

The successful operations of buildings throughout their life or structural expectancy are largely dependent on how well their complementing services are organized from the initiation of the project, and managed in the long run. Especially in the cases of public buildings where huge financial investments need to be accounted for and remain justifiable over time. Also, where user volume or density is high, buildings need to be highly resilient such that they do not require gross amounts of recurring operational or maintenance cost for optimum performance. These extents have characterized building sustainability in recent times with great emphasis on reducing maintenance needs and ensuring the efficiency of building services. As common across every sector, issues of maintenance also plague tertiary institutions as the hold large crowds which their basic infrastructure is meant to cater to on a daily basis. Services within these infrastructures are also expected to perform maximally at all times if user comfort and satisfaction is to be achieved. The Rivers State University is considered one of the most prominent institutions not just in the region it is situated, but also across the country. Being situated in an economically viable region, expectations of the physical representation of infrastructure and built environment practices are equally high. However, the institution remains caught up in the maintenance related quagmire generally recognizable across tertiary institutions in the Nigerian scenario. This study attempts to investigate issues of maintenance of infrastructure at the Rivers State University from a design-based perspective.

\section{PROBLEM STATEMENT}

More than ninety percent of the multi-story structures at the Rivers state university present visible defects related to the poor functionality of services, particularly mechanical related services. Issues of damp in walls, mold growth and discoloration, chalking, creeping plant infestations, cracks and aesthetic irregularities are wide spread across building facades thus creating an ugly scape. This presents a worrisome scenario as there are visible indications of reduction of the life span of these buildings, besides the reduction of value these infrastructure despite the huge capital cost investments. This dire situation requires a critical solution.

\section{MAINTAINABILITY AND BUILDING MAINTENANCE}

Ahmad (1994) proposes that building maintenance is a process by which a building is kept at a predetermined standard for use and benefit of its occupants, users or owners. Also, the business dictionary presents maintenance to refer to activities undertaken to conserve for as long as possible, the original condition of an asset or resource while compensating for normal wear and tear. Maintainability on the other hand is defined as the probability of performing a successful repair action within a given time. In other words, maintainability measures the ease and speed with which a functional system can be restored to operational status after a failure occurs. It is the characteristic of design and installation which determines the probability that a failed equipment, machine, or system can be restored to its normal operable state within a given timeframe, using the prescribed practices and procedures. These extents determine that in discussing the efficiency of building services, while building maintenance is grossly dependent on the available opportunity characterized by maintainability, maintainability in turn is premised on the degree of consideration it is accorded in the design process. However, this association between architectural design and maintenance has continually been regarded as vague in the Nigerian context resulting in the poor efficiency of 
building services in most cases. Arguments exist that most professionals in practice pay little or no thought to maintenance at design stages on the basis that their engagement responsibilities are terminated either at the completion of the design, or once the project has been commissioned. These place building professionals miles away from maintenance needs as at the point which they arise in most cases. The inability to maintain effectively and consequent failure of building services has remained grossly responsible for the epileptic functionality or outright abandonment and dilapidation of building infrastructure nationwide.

\section{MAINTAINABILITY AND THE PRESERVATION OF BUILDING SERVICES}

Issues of building maintenance have remained at the fore front of built environment research and practice since the existence of services in buildings. Various perspectives and theories have been examined towards establishing best responsive approaches to maintainability and maintenance needs. With consistently recurring failure the need for consideration of new dimensions still exists. The concept of culture has been examined with regard to building maintenance with many researchers concluding that poor maintenance culture is responsible for the failure of maintenance initiatives in the Nigerian scenario. A greater portion of these researches have considered culture only beyond the commissioning of the physical structure. However, the concept of maintainability which identifies that maintenance can only be undertaken effectively if sufficient provision has been made in the cause of design, establishes cause for the examination of culture in a new direction.

\section{CULTURE, MAINTAINABILITY AND THE DESIGN PROCESS FOR IMPROVED SERVICE EFFICIENCY}

Right from the pre-colonial era when mud and thatch formed the basic building materials in the region, the inherent characteristics of maintainability were existent in the design process as the selection of material and skill of construction presented an easy context for maintenance to take place. As structures in this era were mostly constructed by their owners, the skill and manpower to tackle maintenance problems was never an issue of concern as solutions were simple and immediately available. The colonial and post-colonial eras brought about new technologies which created a scenario where building owners were not directly responsible for the design and subsequent development of structures and as such lacked the skills for maintenance requirements. This created a culture shock as regards building maintenance considerations and resulted in widespread building dilapidation and depreciation as the designs were conceived outside the country, technology used was foreign to the generality of people, there were no replaceable building materials for the foreign ones used, and not enough skilled technical personnel to carry out such maintenance.

By putting more emphasis at the design stage, the design process could be optimized in such a way that adequate planning on choosing the right materials, structural strength, good workmanship, plants and equipment, skilled labor etc. are made. The sequential nature of design and construction processes as also been highlighted as hindering maintainability. They are only linked at the terminal tail end of each other rather than overlapping and benefiting from one another. If the design process is to be enhanced, the building team (i.e., architects, planners, engineers, contractors and including the clients, maintenance officers and all major actors in the construction industry) need to come together and contribute towards the building's maintainability at the project inception rather than leaving it for the maintenance personnel at the end of construction to battle with the curative measures or emergency maintenance. 
According to Cornick (1996), the root cause of the problems that the construction industry and its clients experience lie in the division of the responsibilities between the design aspect and the construction aspect. Ward (1979) was direct in his criticism of the organization of the construction industry when he noted that the industry is unique in that the design process is separated from production. In building, the Architect designs and the contractor produces whereas in most other industries, for example the motor industry, the designer is employed by the producer.

The successful completion of any building depends on many things, few of which are as important as the architect-contractor relationship. The two parties must be willing to work together so that the clients get maximum benefit from their joint expertise. The contractor should feel able to contribute to the design processes in matters relating to construction practice and the architect should be willing to receive, analyze and subsequently act on such recommendations. The paramount aim of both parties should be to achieve a building that will serve the client's purpose in every way, and which will represent good value for money within the limitations of time and finance available and most importantly forestalling heavy future maintenance problems.

RIBA (1977) developed a plan of work as a model procedure to be adopted to provide a process for the design of any project and a suggestion on the best combinations of the participants to carry out each stage of activities. This was however criticized by Ward (1983), when he pointed out that since the contractor is usually appointed at the tender stage, he makes no contribution until that stage. This divided responsibility has also limited the flow of information in-between the diverse activities and this can only lead to un-coordinated processes. Even with the modern-day information technology, the processes are getting more and more segregated. Computer Aided Design has become mere computer automation for drawing for fancy and visualization rather than for management and for efficiency of the whole construction processes. Different aspects of the industry end up in specializing in segregated parts and each working in as much isolation as possible from others and only meeting at the expiration of one another's exercise. The summary of it is that activities are not overlapping and so not benefiting. All these need to be addressed by bringing all the project team together at the inception of the building to make their contributions for a wellplanned real preventive maintenance.

\section{COMMON CAUSES OF BUILDING MAINTENANCE ISSUES}

According to Stephen (2002) building services rarely perform as well as desired and the causes could emanate from deficiencies in design, construction, tenancy/usage. However, in many cases, issues relating to construction and tenancy arise from design deficiencies. Hence thorough consideration at the design stage can prove a long-term preventive measure in the consideration of maintainability. Unfortunately, by the provision of the normal contract system, designers of buildings rarely have a long-term interest in the buildings they conceived hence, they become divorced from the maintenance problems that follow from their design flaws.

The crucial point this paper therefore emphasizes is strategic role of the design stage and how planning at this stage can influence efficiency during the other stages. Maintenance problems though do manifest during the use of the building, their causes might be during the design stage. 
Speight (1968) was direct in his assertion that it is at the design stage that the Maintenance burden can be positively influenced for better or for worse. Where the designer fails to make adequate consideration for minimizing maintenance problems, it always turns out to be a big problem when the building is eventually occupied for usage. The consideration for effective maintenance should therefore start from the design stage. Decisions taken at this stage should always have maintenance as one of the parameters for the building design. Cheetham (1972) also described how the occurrence of defects in the building fabric could result from many unrelated designs such as unsuitable materials, incorrect assessment of loads and inadequate assessment of exposures.

According to Arayela \& Adams (2001), it is often said that building defects start on the drawing board, but in some cases, they can originate at an earlier stage. Inadequate brief may lay down totally unrealistic cost limits or fail to give vital information on the functional requirements of the building. Design deficiencies could result in a building disaster if adequate attention is not paid to the design of bearing support, calculation errors, deformation, shrinkage problems, errors in assumed loading (especially wind), and changes in alteration of existing structures- all these could contribute substantially to building failures and disasters. Therefore, adequate attention needs to be paid to these factors during design stage.

For Zubairu (2001), the extent to which the various factors contribute to maintenance problems in government office buildings in Nigeria is as follows: Inadequate architectural design 6\%, Inadequate Structural design 7\%, Inadequate Electrical design 9\%, Inadequate Mechanical design 11\%, Poor Construction 12\%, Use of poor-quality components and materials $14 \%$, Natural deterioration due to age and environment $18 \%$, Misuse by occupants $18 \%$ and Others 5\%. According to Assaf (1996), design and construction faults that affect maintenance of buildings are in eleven groups as he adds defects due to specification, design defects in maintenance practicability and adequacy, and defects due to contractual administration to Zubairu's (2001) mention. They could be controlled or minimized during the design stage.

\section{BUILDING MAINTENANCE ISSUES AT THE RIVERS STATE UNIVERSITY}

An analysis of buildings at the Rivers State University presents above ninety percent of physical infrastructure are currently under one form of dilapidation or failure, resulting largely from the poor orientation, design or fixture of building services. As such, the services which are meant to complement the building functionality have now become a primary source of its degradation. The figures presented below show current statuses of learning blocks, administrative offices, hostels and union buildings as no form of physical infrastructure seems to be left out. This raises cause for alarm. As premised on this discourse, most of these issues seem to be design related. These include the following:

a/ Extensive use of conduit systems for plumbing lines instead of provision of duct systems for easy maintenance

b/ Poor designing of rain and surface water collection systems

c/ Poor roof system designs 
Journal DOI: $\underline{\text { www.doi.org/10.46654/ij.24889849 }}$

Vol. 7, Issue 4 (April, 2021) | www.ijaar.org

Article DOI: www.doi.org/10.46654/ij.24889849.e7420

d/ Poor consideration for HVAC systems and outdoor units resulting in wall dampening

e/ Inadequate consideration of electrical systems

f/ Poor consideration for viable systems like false ceilings and floors

g/ No detailing to established underground lines, pipe works or cable trenches for ease of maintenance

$\mathrm{h} / \quad$ Absence of dedicated service/control rooms for efficient monitoring of building usage

i/ Poor specifications for service components

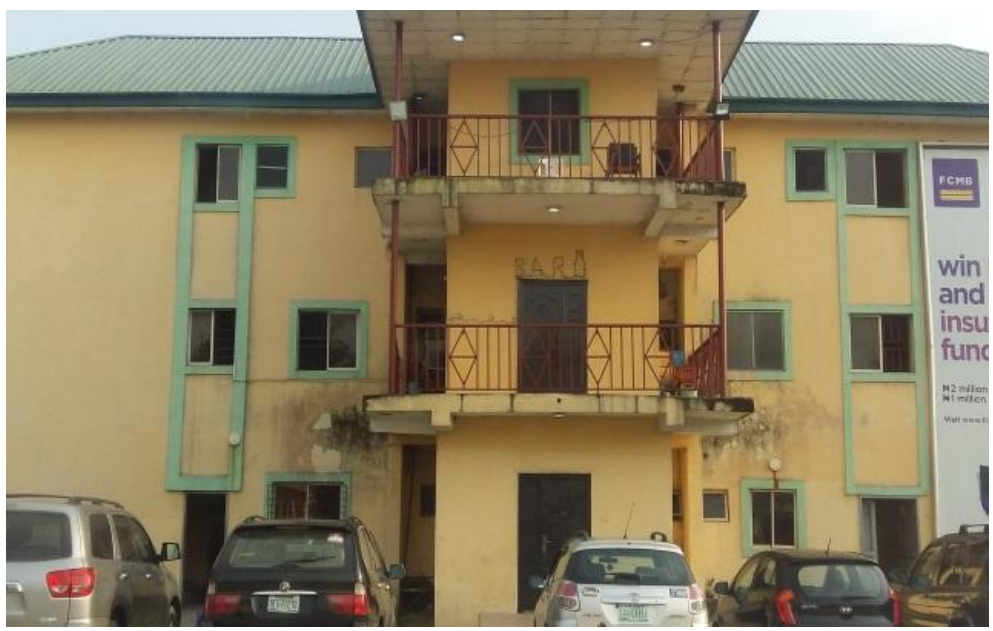

Figure 1: showing the entrance to the post-graduate hostel at R.S.U Source: Author

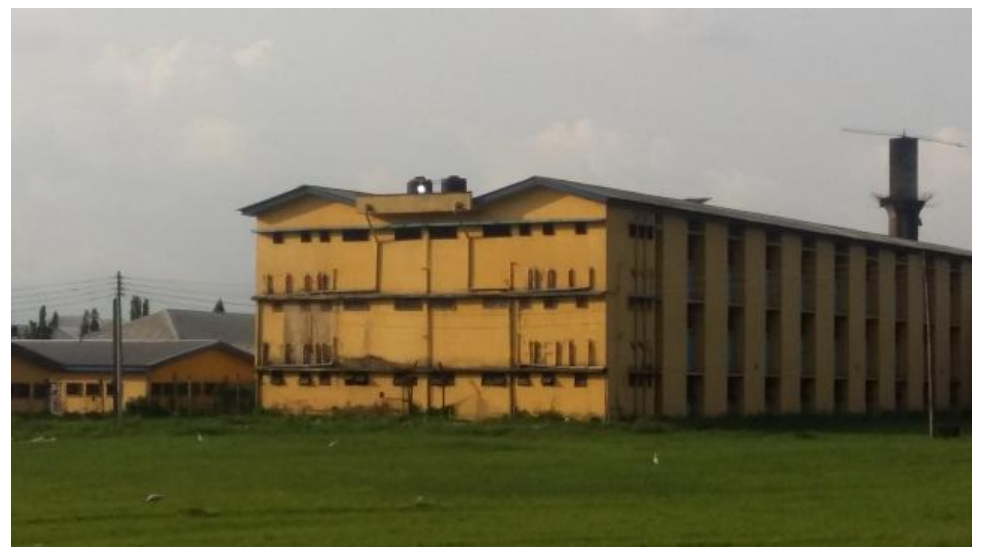

Figure 2: Showing Hostel D at R.S.U

Source: Author 


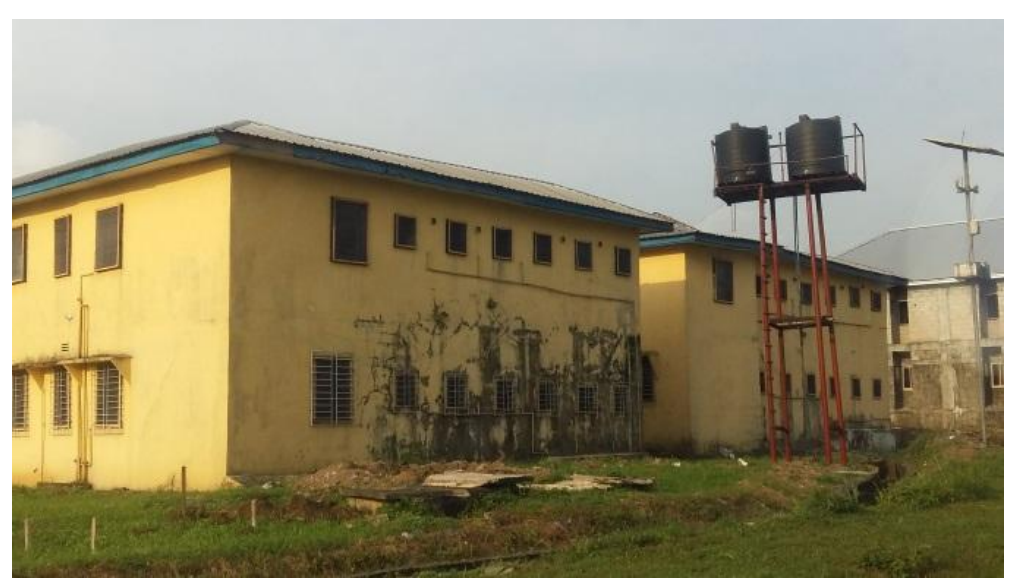

Figure 3: Showing Hostel D at R.S.U Source: Author

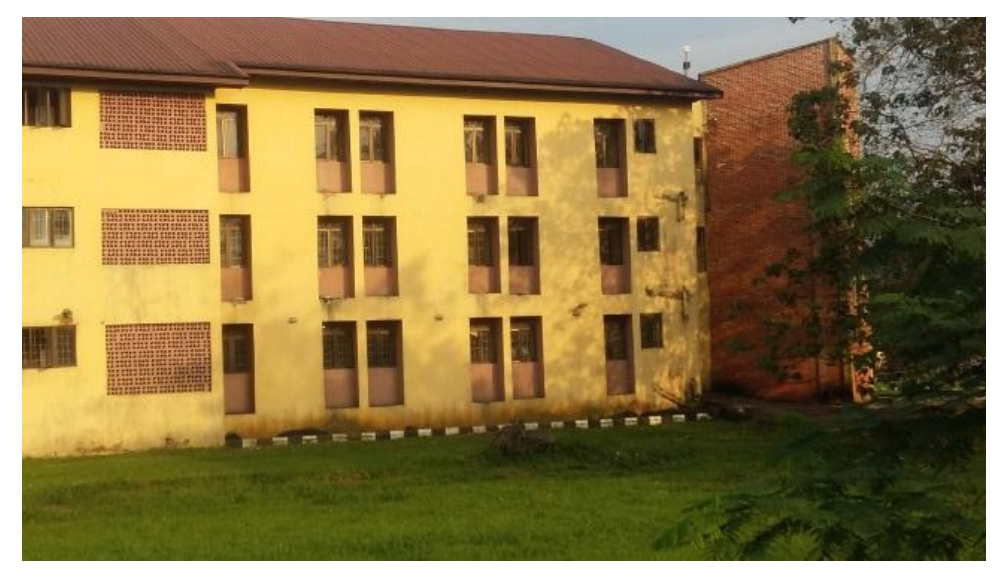

Figure 4: Showing NDDC Hostel at R.S.U Source: Author

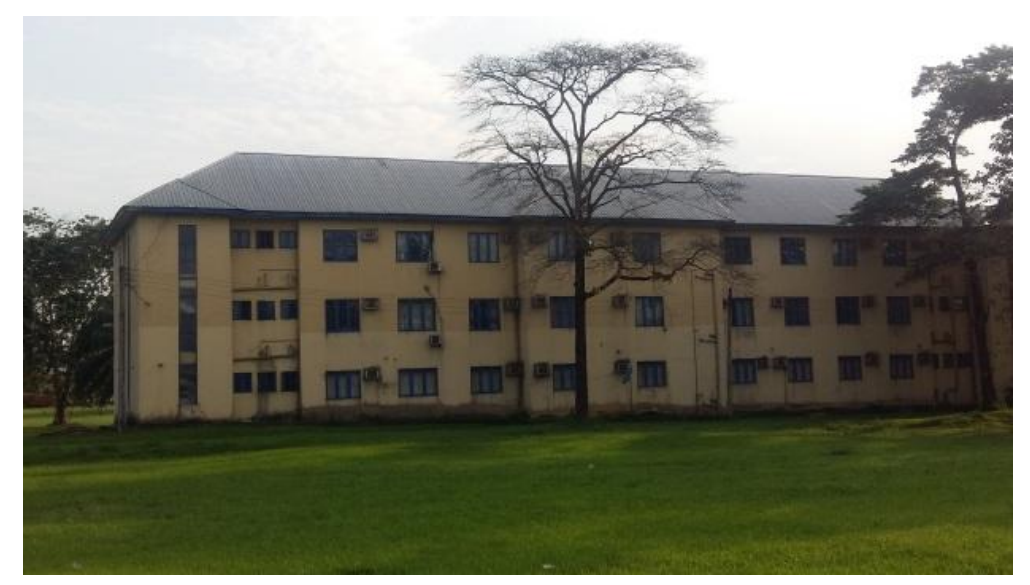

Figure 5: Showing Department of food science office building at R.S.U Source: Author 
Journal DOI: www.doi.org/10.46654/ij.24889849

Vol. 7, Issue 4 (April, 2021) | www.ijaar.org

Article DOI: www.doi.org/10.46654/ij.24889849.e7420

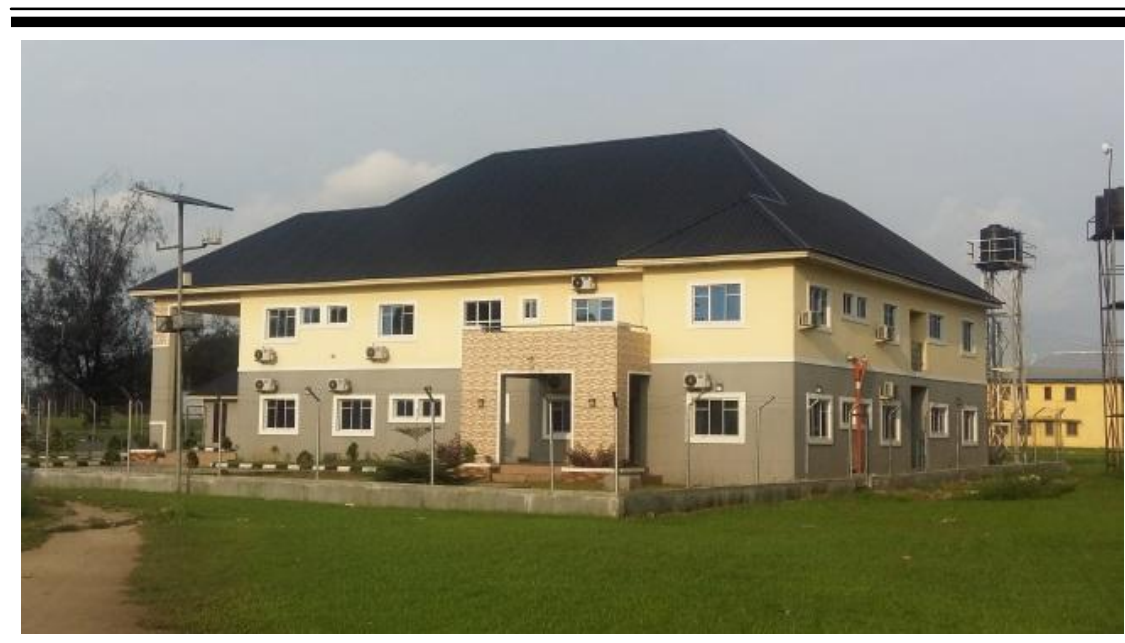

Figure 6: Showing Student Union Government building at R.S.U

Source: Author

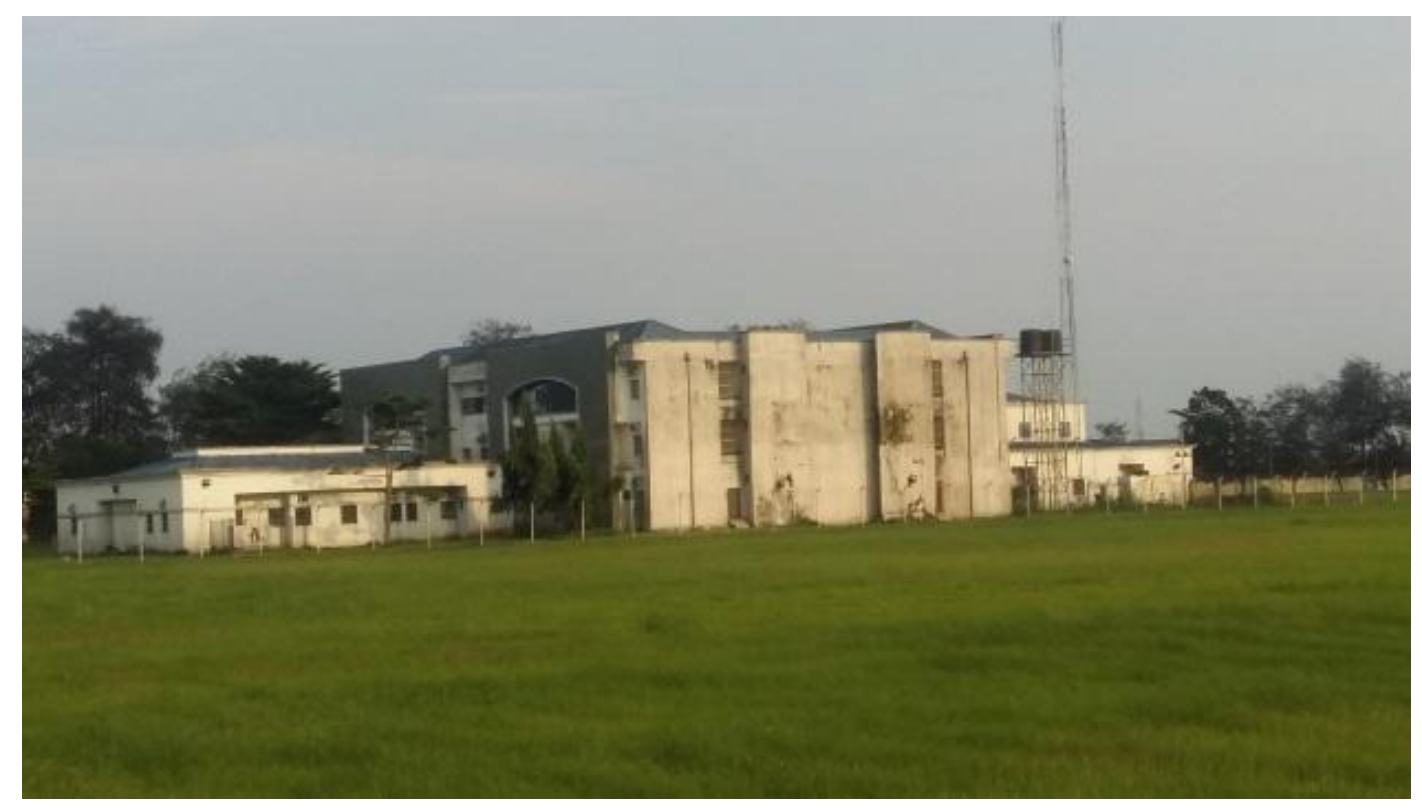

Figure 7: Showing the senate Building at R.S.U

Source: Author 


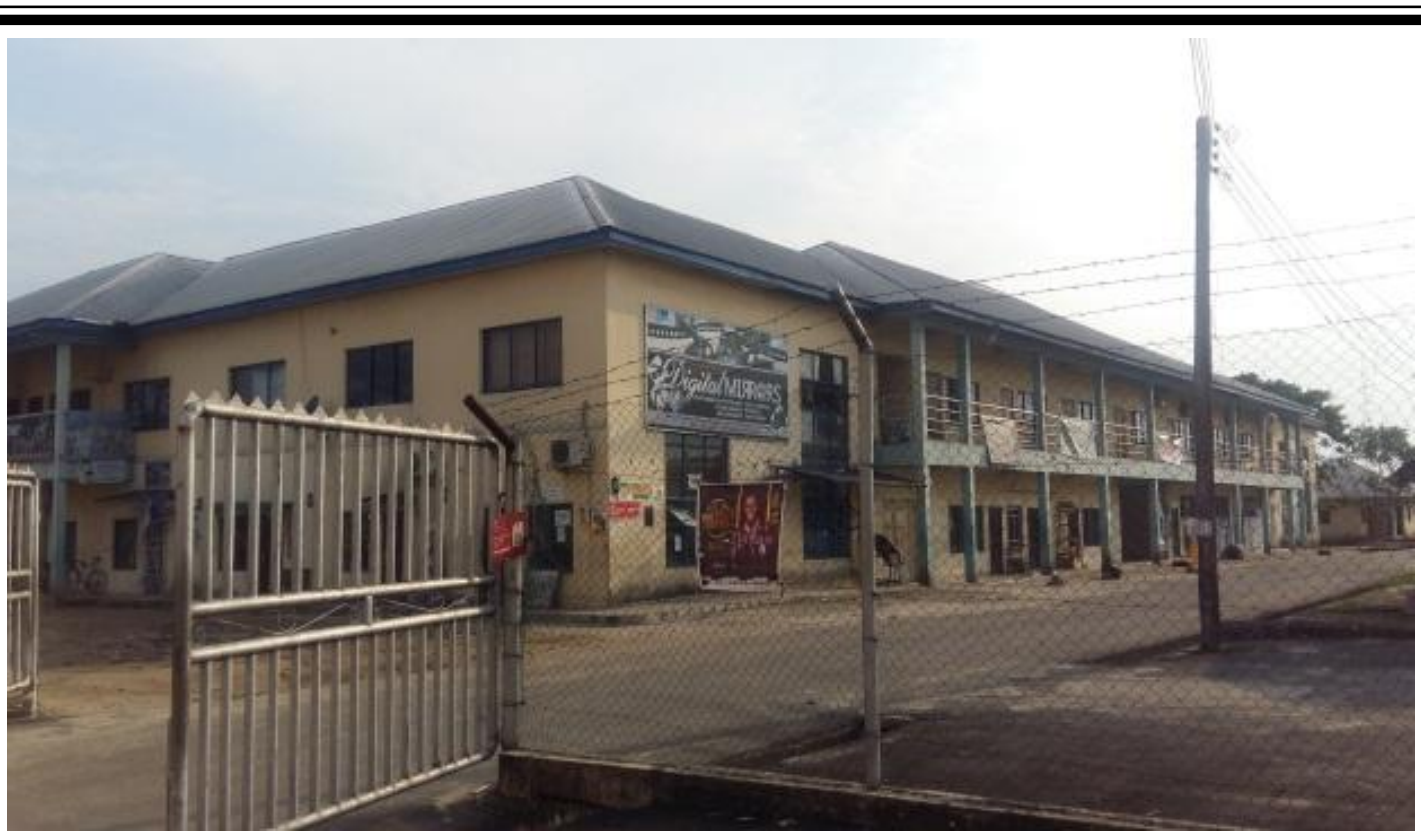

Figure 8: Showing the Shopping Complex at R.S.U

Source: Author

\section{DESIGN COMPONENTS FOR MAINTENANCE STRENGTHS}

Adejimi (1998) enlists twelve major factors identified as maintenance strengths from a study for Effective Maintenance of Public Buildings in Lagos State which if considered at design stage can optimize maintainability. Among these, design resolution, material specification, and building maintenance manual are considered key to optimal maintainability in the design process.

\section{Design Resolution}

The architect needs to sincerely ask himself whether the design has been totally resolved to suit the owner's or users' taste. A poorly resolved design eventually results in serious maintenance problems. An un-detailed design results in a poorly finished building. A poorly resolved building design does not suit the owner and are unlivable as conversions of the functional spaces go on daily in order to adjust to satisfy the users' needs. This leads to the breaking and cracking of the component parts weakening the structure and fabric of the building. The more the design is made to satisfy the functional, aesthetic and the convenience of the users, the less the breaking and conversion of its parts.

\section{Specification of Materials}

The durability, appropriateness, replace-ability and cost of the specified materials and components can determine the maintainability of the building. The designers must therefore ask themselves if the materials they are specifying will satisfy the above conditions. This is because while some materials may be more durable, weatherproof, aesthetically pleasing, and cheap, some others may be costly, unavailable for replacement and not easily re-fixable. The more the number of irreplaceable components on a building, the higher the maintainability problem of the building. 


\section{Maintenance Manual}

If every electronic item bought always come with operating manual, a building which is more costly, durable and complex needs more than production blueprint (Working Drawings) which most clients do not even know how to read. Architects need to provide a maintenance manual together with the working drawings. Such manuals on the 'dos and don'ts' of how to use the facility should be part of the design documents right from the design stage. This is why the facility managers (maintenance managers) need to be part of the design team from its inception. The architect should therefore as a matter of duty give the client adequate instruction on how to maintain the building after the construction. The main idea here is to make these design components as much as possible parts and parcels of the design exercise as inputs so that Architects, Engineers and other co-designers can always and unforgettably think maintenance constantly as they design buildings.

\section{CONCLUSION}

This study has reviewed the concept of culture as it relates to maintenance in buildings, identifying the critical point of the design stage where it must be introduced such that it forms a solid foundation for the subsequent courses of the project. Paying attention to maintenance culture in the design stages will improve maintainability possibilities immensely. The study establishes the existence of infrastructural problems at the rivers State University and identifies the need for design-oriented solutions.

\section{RECOMMENDATIONS}

The study recommends the enactment of policies that building within the university must take cognizance of best maintenance strategies and make adequate provisions for maintainability right from the design stages and must be duly verified before approvals.

The study also recommends the constitution of a building maintenance unit made up of seasoned professionals who understand the strategic role of maintainability in extending building life span as against general work artisans. 


\section{REFERENCES}

Adejimi, A. (1998); Optimizing Management of Design Processes for Effective Maintenance of Public Buildings in Lagos State. A M.Sc. Thesis Delivered in the Department of Building University of Lagos, Nigeria.

Arayela \& Adams (2001); Building Disasters and Failures in Nigeria: Causes and Remedies; AARCHES Journal, Vol 1 No 6 pp.71

Assaf, S. (1996); Effects of Faulty Design and Construction In, Building Maintenance Journal of Performance of Constructed Facilities, Nov.pp. 171.

Cheetham, D. W. (1972); Defects in Modern Buildings, Building Journal,July pp. 18

Cornick, T. (1996); Computer Integrated Building Design;'E\& FN Spon,London, p. 7 - 23.

Iyagba, R. O. (1986); Maintenance at Design Stage. A Paper Presented at a Seminar onPublic Building Maintenance in the Department of Building,University of Lagos, Nigeria. 6th-8th, Aug. 1986.

Speight, B. A. (1968); Maintenance of Buildings - Its Relationship to Designthe Chattered Surveyor, Oct.pp. 31; 177.

Stephen, J.H. (2002) Building Services Maintenance-The Forgotten Discipline; Aha Management Publications; www.aha.com.au/energy1.htm.

Zubairu S.N. (2001); The Most Frequently Recurring Maintenance Problems inGovernment Office Buildings in Nigeria, NIAJ, Vol ii, No 8-12.pp.36. 